Canadian

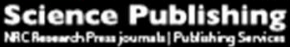

Canadian Journal of Zoology Revue canadienne de zoologie

\title{
Temporal variation in habitat use, co-occurrence, and risk among generalist predators and a shared prey
}

\begin{tabular}{|r|l|}
\hline Journal: & Canadian Journal of Zoology \\
\hline Manuscript ID & cjz-2015-0127.R1 \\
\hline Manuscript Type: & Article \\
\hline Date Submitted by the Author: & 20-Nov-2015 \\
\hline Complete List of Authors: & $\begin{array}{l}\text { Bastille-Rousseau, Guillaume; Trent University, Environmental and Life } \\
\text { Sciences } \\
\text { Rayl, Nathaniel; University of Massachusetts, Department of Environmental } \\
\text { Conservation } \\
\text { Ellington, Edward; Trent University, Environmental and Life Sciences } \\
\text { Schaefer, J.A.; Trent University, Environmental and Life Sciences; } \\
\text { Department of Biology } \\
\text { Peers, Michael; Trent University, Environmental and Life Sciences } \\
\text { Mumma, Matthew; University of Idaho, Department of Fish and Wildlife } \\
\text { Sciences } \\
\text { Mahoney, Shane P.; Conservation Visions Inc. } \\
\text { Murray, D.L.; Trent University, Environmental and Life Sciences; } \\
\text { Departments of Biology and Environmental }\end{array}$ \\
\hline Keyword: & \begin{tabular}{l} 
PREDATION < Discipline, MOVEMENT < Discipline, MAMMALIA < Taxon \\
\hline \hline
\end{tabular} \\
\hline
\end{tabular}

\section{SCHOLARONE"}

Manuscripts 


\section{Temporal variation in habitat use, co-occurrence, and risk among generalist predators and a} shared prey

Running heading: Risk among generalist predators and prey

Guillaume Bastille-Rousseau*a, Nathaniel D. Rayl ${ }^{b}$, E. Hance Ellington ${ }^{a}$, James A. Schaefer ${ }^{a}$, Michael J.L. Peers ${ }^{a}$, Matthew A. Mumma ${ }^{c}$, Shane P. Mahoney ${ }^{d}$, and Dennis L. Murray ${ }^{a}$

${ }^{a}$ Environmental and Life Sciences Graduate Program, Trent University, Peterborough, Ontario, K9J 7B8, Canada

${ }^{b}$ Department of Environmental Conservation, University of Massachusetts, Amherst, Massachusetts, 01003, USA

${ }^{c}$ Department of Fish and Wildlife Sciences, University of Idaho, College of Natural Resources, Moscow, ID 83844, USA

${ }^{c}$ Conservation Visions Inc, P.O. Box 5489 - Stn C, 354 Water St, St. John's, Newfoundland and Labrador, A1C 5W4, Canada

* Corresponding author: gbastill@esf.edu, (315) 751-8559

Present address: Department of Environmental and Forest Biology, SUNY-ESF, Syracuse, New York, 13210, USA 


\section{Abstract}

Generalist predators typically have broad diets, but their diets may become constrained when one species of prey becomes disproportionately available. Yet there is poor understanding regarding whether generalist predators exhibit stereotypic relationships with pulsed prey resources. We used telemetry data from 959 woodland caribou (146 adult females, 813 calves; Rangifer tarandus (L. 1758)), 61 coyotes (Canis latrans Say, 1823), and 55 black bears (Ursus americanus Pallas, 1780), to investigate how two generalist predators interacted with caribou neonates on the island of Newfoundland. We examined the similarity of patterns of habitat use between caribou and their predators across time and related this similarity to interspecific spatiotemporal co-occurrence and mortality risk for caribou neonates. The similarity in habitat use between coyotes and caribou mirrored variation in juvenile hazard risk, but had weak association with actual co-occurrence with caribou. Bears and caribou exhibited less similarity in habitat use during the calving season than coyotes and caribou. The relationship between habitat use of bear and caribou did not correspond with either co-occurrence patterns or overall risk for caribou neonates. Our work illustrates how risk for a prey species can be shaped differently based upon differences between the behavioural-strategies of generalist predator species.

\section{Keywords}

Black bear (Ursus americanus), caribou (Rangifer tarandus), coyote (Canis latrans), neonates, Newfoundland, predator-prey interactions, specialist-generalist predators 


\section{Introduction}

Predation is a key force shaping most ecosystems (Getz 2011) and one of the key drivers of animal evolution (Roff 1996). Predator-prey interactions are generally conceptualized as complex games of fear and stealth between predators and prey (Brown et al. 1999). In these games, predators attempt to maximise their success during search, encounter, and attack stages through selective movement, patch-use, and hunting behaviour (Lima and Dill 1990; Hebblewhite et al. 2005). Conversely, prey attempt to minimise the impact of predators by balancing their immediate survival with the acquisition of resources, reproduction, and maintenance of other long-term survival requirements (Stephens and Krebs 1986; Brown 1999). Despite varying outcomes of the predator-prey game, theoretical models generally imply a positive relationship between predator and prey regarding spatial overlap and encounter risk which subsequently modulate predation risk (Sih 1984; Laundré et al. 2001; Mitchell and Lima 2002). These models are useful because they consider processes such as encounter and vulnerability when generating predictions of predator and prey resource use and distribution over the landscape (Lima and Dill 1990). However, these models have rarely considered the variation that is often inherent in species' behaviour and temporal changes in resource use.

Models examining how predator hunting mode and habitat use determine the magnitude of consumptive and non-consumptive effects on prey have been proposed and reviewed (Schmitz 2005; Preisser et al. 2007). These models have established that hunting strategy is a key element of any predator-prey game. Unfortunately, models such as the shellgame or the landscape of fear, even if they consider predator behaviour, are typically oriented towards specialist predators and their primary prey (Laundré et al. 2001; Mitchell and Lima 
2002). To date, other types of predators, such as generalist predators that do not rely on a particular prey type unless environmental conditions become conducive to exploitation of that particular prey type (e.g., because of high relative density or vulnerability of a given prey type), are poorly understood. This includes many generalist predators that exhibit stereotypic hunting strategies suited to one vs. multiple prey types (but see Schmidt et al. 2001; Schmidt 2004).

Predation risk from generalist predators is a function of similarity in habitat use between predator and prey (enemy-free space; Schmidt 2004), movement strategies leading to encounter (Mitchell and Lima 2002; Bastille-Rousseau et al. 2011), and inherent vulnerability of the prey (Lima and Dill 1990). Yet not all generalist predators are necessarily cut from the same cloth; in many cases there may be individual-level variation in kill rates of a particular prey species within a predator population (Bolnick et al. 2003). For example, variability in prey vulnerability may result because of differences in age or experience of individual predators (Woo et al. 2008). It follows that a detailed understanding of predator-prey interactions requires information on population-level and individual-level patterns (Woo et al. 2008; Bastille-Rousseau et al. 2011), especially since the effect of a small number of specialized individuals can sometimes have major impacts on prey populations (Festa-Bianchet et al. 2006).

Here, we investigate how predation risk for a prey species, woodland caribou (Rangifer tarandus (L. 1758)), is impacted by the behaviour of two omnivorous species, coyote (Canis latrans Say, 1823) and American black bear (Ursus americanus Pallas, 1780, hereafter "bear") on the island of Newfoundland. Combined, the two predators are responsible for the majority of caribou calf mortalities in Newfoundland, each killing approximately $30 \%$ of calves within the first two months of life (Bastille-Rousseau et al. 2015). After this point calves are less 
vulnerable to predation; however, coyote and bear predation events still occur (Lewis and Mahoney 2014). Yet, in Newfoundland for both predators caribou calves are only one of many food items consumed, even during the period of high calf vulnerability (C. Zieminski unpublished data; Bridger 2005). In Newfoundland, black bears consume vegetation, soft mast, and ants (Formicidae Latreille, 1809). Coyotes consume snowshoe hares (Lepus americanus Erxleben, 1777), red squirrels (Tamiasciurus hudsonicus Erxleben, 1777), southern red-backed voles (Myodes gapperi Vigors, 1830), beavers (Castor canadensis Kuhl, 1820), and soft mast. Both predators prey on moose (Alces alces L. 1758) and caribou calves and consume hunting- or winter-related carrion when they are available. To understand caribou-predator interactions, we first defined ecologically relevant seasons (characterized by periods of homogenous resource use and movements) for each species by applying a clustering algorithm approach developed by Basille et al. (2012). We then examined how predators and caribou use similar habitat at the population and individual levels during our ecologically derived seasons, and how this relates to interspecific co-occurrence in space and mortality risk for neonate caribou. Since bears and coyotes are generalist predators, they may take advantage of the pulse of predictable and easily captured caribou calves in different ways (Zager and Beecham 2006; Turner et al. 2011), thereby decoupling the concordance among habitat use, co-occurrence and mortality risk. For example, if the risk for caribou neonates is driven by a change in multi-scale patterns of predator space-use, we predict that higher similarity in habitat use between predator and prey will result in higher risk and be associated with higher co-occurrence. If the risk for caribou neonates is driven solely by calf intrinsic vulnerability with no behavioural change in predator space-use, we expect no correlation between habitat overlap, co- 
occurrence, and risk. Our study provides a deeper understanding of the various potential spatio-temporal interactions that may occur between predators and prey at both the population- and individual-level.

\section{Material and Methods}

\section{Data Collection}

Newfoundland $\left(47^{\circ} 44^{\prime} \mathrm{N}, 59^{\circ} 28^{\prime} \mathrm{W}\right.$ to $\left.51^{\circ} 44^{\prime} \mathrm{N}, 52^{\circ} 38^{\prime} \mathrm{W}\right)$ is a $108,860-\mathrm{km}^{2}$ island off the east coast of Canada, with humid-continental climate and ample year-round precipitation (Environment Canada 2013). Natural habitat consists mainly of coniferous and mixed forests of balsam fir (Abies balsamea (L.) Mill), black spruce (Picea mariana (Mill.) Britton, Sterns \& Poggenb.), and white birch (Betula papyrifera Marshall), and in some locations substantial areas of bogs and heath or barrens. Newfoundland caribou differ significantly from most other caribou populations as they are not exposed to wolf (Canis lupus L. 1758) predation because wolves were extirpated from the island in the 1920s. Our analyses were based on a series of Landsat 7 scenes with a resolution of $30 \mathrm{~m}$, which we classified into eight habitat types: wetland habitats (Wetland), mixed and deciduous stands (Mixed), coniferous stands (Conifer), coniferous scrub (Scrub), barren, rocky and other open habitats (Barren), open water (Water), lichen and heathland (Lichen) and rarer habitats such as recent ( $<40$ years) disturbances and fire (Other).

During 2006-2013, > 200 adult female caribou, 89 black bears (>2 years of age), and 61 coyotes ( $>1$ year old) were captured and fitted with global positioning system (GPS) collars that obtained locations every 1, 2, or 4 hours. Caribou were captured from 6 herds, but predators 
were only captured around and within the range of three of these herds. Predator dispersal eventually resulted in overlap between the caribou monitored in all herds and the monitored predators. We focused our analyses on animals followed for at least 3 consecutive months per year that had $>90 \%$ of their locations in areas with Landsat data, resulting in 146 adult caribou females ( 552 caribou-years and 1,689,519 locations), 55 black bears ( 22 F, 33 M, 142 bear-years and 128,174 locations), and 61 coyotes (23 F, 38 M, 94 coyote-years and 68,491 locations).

We monitored the fate and estimated the survival time of 813 calves in 5 of the 6 herds, 2003-2013, using very high frequency (VHF) telemetry. We located calves by helicopter and captured them on foot, generally 1 to 3 days following birth. We verified that collared calves rejoined their mothers within 24 hours of capture. Aerial monitoring schedules varied across years, from every 2-4 days in June and early July, every 5-10 days until the end of August, and fortnightly to monthly thereafter. When a VHF collar indicated mortality, we conducted investigations to determine the most likely cause of death (black bear, coyote and other). Survival data were used in the hazard risk calculation (see "Hazard risk" below). All animal capture and handling procedures were consistent with the American Society of Mammologists guidelines (Sikes and Gannon 2011).

Statistical Analysis

Seasons

Although most caribou calf mortalities occurred during the calving season, we conducted all analyses throughout the year, both because predators killed some calves outside of the calving season, and to gain a better understanding of how predator-prey interactions 
fluctuated across time. We followed the approach of Basille et al. (2012) to define ecologically based seasons derived from space-use patterns for each species using a clustering approach. For each day in a given year we characterised the space-use of an individual across 11 habitat and movement variables (see Figure S1, for habitat types) by calculating the mean speed, tortuosity, average elevation, and the proportion of locations in our 8 habitat categories (habitat use) within a 15-day moving window centered on the focal day. We then rangestandardized each daily individual-year measurement between 0 and 1 and averaged them, first by individual, and then by species to come up with a value for each day of the year (Basille et al. 2012). This ensured that a behaviour displayed prominently in a given year or by an individual monitored over multiple years did not contribute disproportionately to our classification. We used K-means clustering to identify homogenous periods based upon our 11 habitat and movement variables (Basille et al. 2012) and determined the optimal number of clusters using the DD-weighted gap method (Yan and Ye 2007). We used the optimal number of clusters as the number of biological seasons. We performed a bootstrap approach where 100 sets of individual-years were resampled with replacement from the original dataset and then ran Kmeans clustering for each set to assess the robustness of the classification, calculating the probability that each day fell in a specific season (Basille et al. 2012). Finally, delineations based on seasons that started on a day that fell in the top $20 \%$ (for caribou), $25 \%$ (for coyote), or $30 \%$ (for bears) of the weight distribution were obtained. We adjusted criteria for predator species to ensure a representative seasonal delineation in regards to their biology in Newfoundland and minimal number of seasons expected (e.g., for bears, defining the criteria below $30 \%$ led to the identification of only two seasons, active and denning, despite non-homogenous 
movements and habitat use [see Supplementary material]). Because tortuosity requires animals to move, and bears were stationary during denning, we randomly assigned tortuosity values from a uniform distribution ( $0-\pi$ radians) and used habitat variables associated with den sites for all days when individuals were denning. Next, we created caribou-predator seasons by taking the intersection of caribou and predator delineations (hereafter, "caribou-predator seasons"). Thus, the end of each caribou-predator season delineated a behavioural adjustment in space use by either caribou or the predator species. We then evaluated habitat overlap, cooccurrence, and hazard risk from bear and coyote using the caribou-predator seasons to test our predictions. We also created bear-coyote seasons in the manner described above to evaluate the similarity of habitat use between bears and coyotes.

\section{Similarity in habitat use}

We examined similarity in habitat use between caribou and each predator species at two levels, population and individual. For caribou, we used adult female GPS telemetry regardless of their reproductive status as this information was not available; parturition rate was approximately $80 \%$ during the monitoring period (Weir et al. 2014). Population-level similarity reflects overlap in habitat use of the caribou population with a predator population, whereas individual-level overlap reflects overlap between an individual predator and the caribou population. Overlap in habitat use may be an indication of the strength of potential trophic interactions between predator and prey species as this is prerequisite to predator-prey co-encounter (Hebblewhite et al. 2005; Chesson and Kuang 2008). We evaluated habitat overlap using an index of overlap derived from the Jaccard index adapted to continuous data (see Basille et al. 2012 for further details). For each habitat type and each day, habitat overlap 
at the population- or individual-level was measured as the size of the intersection over the size of the union of a caribou population range and either a predator population species range or individual range based on maximum and minimum values for a given day:

Habitat $($ Caribou, Predator $)=\frac{\min [\max (\text { Caribou }), \max (\text { Predator })]-\max [\min (\text { Caribou }), \min (\text { Predator })]}{\max (\text { Caribou, Predator })-\min (\text { Caribou, Predator })}$

where min and max represented the minimum or maximum values for use (percent of locations) of a specific variable (habitat) within a daily moving window used in the clustering approach. For both levels of habitat overlap, the index varied between 0 and 1 (no overlap to complete overlap) for each habitat and day. We then computed a measure of daily global overlap by taking the average of all habitats for each day for each caribou-predator season. We used a paired T-test to test whether caribou-bear overlap was higher than caribou-coyote overlap. We also assessed bear-coyote overlap to evaluate potential interactions between the predators.

As an additional exercise, to investigate possible specialization towards caribou within predator populations, we examined whether individual-level habitat overlap between predators and caribou could be linked with individual characteristics of predators. For each caribou-predator season, we assessed whether individual habitat overlap was influenced by predator age (adult vs. subadult), gender, and, for coyotes, social status (resident or transient; E.H. Ellington, unpublished data) We used linear models with each of these variables as a single effect and interactions between age and gender for each predator species and each cariboupredator season. We present results for this analysis in Table S1, Supplementary material.

Co-occurrence index (encounter) 
We estimated caribou-predator co-occurrence rates using our GPS telemetry dataset. We considered an encounter to have occurred when an individual and a predator were $<1 \mathrm{~km}$ of apart within a 24-hour window. Detection distances of 1-2 km have frequently been used to identify short-term predation risk in different large mammal predator-prey systems and are likely within predator sensory detection range (Muhly et al. 2010; Whittington et al. 2011). Though such an encounter may not indicate that a biological encounter occurred (predator notices prey or vice-versa), they represent instances where an encounter could plausibly have occurred. Latombe et al. (2013) found behavioural changes in caribou selection following the presence of a wolf within $4.7 \mathrm{~km}$ in the previous 1.5 days, although smaller distances are to be expected for coyotes or bears (Chamaillé-Jammes et al. 2014). Our radius was therefore more conservative than those generally used in definitions of encounter using GPS telemetry (e.g. Muhly et al. 2010; Whittington et al. 2011). To account for any differences in the length of season and intensity of monitoring, we standardized the number of encounters per cariboupredator season by the length of shared days of monitoring, the intensity of monitoring, and the spatial overlap between caribou and predators. The encounter index for a season was computed as:

Encounter $=\frac{E_{S}}{\sum_{i}^{n}\left(D_{S i} * F c_{S i} * F p_{S i} * O_{S i}\right)}$

where $E_{s}$ was the total amount of encounters in a season $S, D_{S i}$ was the number of shared days of monitoring for a specific pair of animals I of $n$ possible caribou-predator pairs, $F c_{S i}$ and $F p_{S i}$ were the average number of fixes per day for caribou and predator, respectively, in a season, and $O_{S i}$ was the percent overlap between caribou and predator $100 \%$ seasonal minimum 
convex polygon home-ranges. For each predator species, we range-standardised between zero and one values of the index over the year.

Hazard risk

Using our dataset of calf survival fate, we estimated mortality risk for caribou calves from predation by coyote and black bear. We estimated the hazard function representing the instantaneous risk of mortality from a given predator for each calf following capture. On average, calves were born approximately 1 June in Newfoundland (Lewis and Mahoney 2014). We used kernel-based methods to estimate a smoothed hazard function, using local bandwidth selection algorithms and an Epanechnikov boundary function (Griffin et al. 2011). Hazard was also range-standardized between zero and one for both species. We tested for correlation between habitat overlap, co-occurrence, and risk with Pearson's correlation coefficients using values averaged over each caribou-predator seasons. All analyses were conducted in R 3.0.2 with packages adehabitatHR, sp rgeos, plyr, muhaz, and functions available from Basille et al. (2012; http://ase-research.org/basille/seasonality).

\section{Results}

\section{Caribou-predator Seasons}

The dDgap statistic revealed the presence of three space-use modes (clusters) over the year for caribou in Newfoundland. These three clusters corresponded to four caribou-specific seasons (Winter, Calving, Summer, and Rut [Breeding]; Figure 1) delimited by the respective starting dates: 26 September, 26 April, 27 June, and 9 September. For black bears, the dDgap statistic showed two local maxima, the highest dDgap statistic indicated only two seasons, which 
differentiated between active and denning periods. Therefore, we used the second highest local maxima, which revealed five clusters and seasons that corresponded more closely to our biological expectations of bear behaviour and patterns of movement and habitat use (Denning, Spring, Summer, Fall, and Pre-denning; Figure 1) with the respective starting dates: 28 October, 15 April, 30 May, 1 August, and 10 October. For coyote, the dDgap revealed six clusters, which corresponded to four seasons (Early Winter, Late Winter, Summer, and Fall) with the following break points: 20 February, 13 April, 12 August, and 31 October. Based on the temporal intersections between species, we identified eight caribou-coyote seasons and nine cariboubear seasons. For a detailed description of seasonal characteristics of movement parameters and habitat use, see Figures S1, S2, S3 in Supplementary material.

\section{Population- and Individual-level Similarity in Habitat-use}

Population-level habitat overlap between caribou and bear was highest in late summer and early fall (August to mid-October) and lowest in the periods following den emergence (up to late-May, Figure 2). Habitat overlap between individual bears and the caribou population followed similar trends at the individual-level (Figure 2). Some individual bears nevertheless displayed stronger overlap with caribou throughout most of the summer period (late April to early September, Figure 2).

On average, annual population-level habitat overlap between caribou and coyote (mean overlap $=0.167)$ was higher than between caribou and bear during the bear non-denning period $($ mean $=0.098, t=-13.126, \mathrm{df}=195, p<0.001$ ). Population-level habitat overlap between caribou and coyote was highest in the summer, most notably between late-June to 
mid-August, whereas it was lowest during late winter (Mid-February to late-April, Figure 2). Habitat similarity between individual coyotes and the caribou population followed a different pattern, however, with average individual-level overlap slightly higher during early winter (November to February) and spring (late-April to late-June) and lowest during late winter and late summer (mid-August to late-September and early-November to mid-February, Figure 2). Variation in individual-level habitat overlap was largest during the early winter and early spring periods (late April to late June, Figure 2). Overall, overlap between bears and coyotes was higher than overlap between caribou and either predator (Figure 2).

Relationships between Habitat Overlap, Co-occurrence, and Risk

We observed that the hazard risk for caribou calves from black bears decreased through time, with the encounter rate between bears and caribou at its highest during the period of high calf vulnerability. Over the year, there was small correspondence between patterns of overlap and risk $(R=0.437, t=1.284, d f=7, p=0.240)$, and even less correspondence between encounter rates and risk $(\mathrm{R}=0.406, t=1.175, \mathrm{df}=7, p=0.278)$ or encounter rates and overlap $(\mathrm{R}=0.061$, $t=0.161, \mathrm{df}=7, p=0.877)$.

For coyotes, hazard risk for caribou calves decreased most abruptly from June to October, and then decreased gradually over the rest of the year (Figure 2). This pattern of risk generally matched population-level habitat overlap between coyotes and caribou $(\mathrm{R}=0.950, t=7.475$, $\mathrm{df}$ $=6, p<0.001$ ), except for the early period of calving when risk was higher and overlap was close to average. The patterns of encounter rate were also correlated marginally with the 
patterns in habitat overlap $(\mathrm{R}=0.719, t=2.315, \mathrm{df}=5, p=0.068)$ and significantly with risk $(\mathrm{R}=$ 0.773, $t=2.721, \mathrm{df}=5, p=0.042$, Figure 2).

\section{Discussion}

We explored spatial interactions between predators and prey at the population and individual level to further our understanding of predator-caribou behavioural interactions leading to caribou calf mortalities in Newfoundland. We first explored seasonal patterns of space-use for each species (Figure 1) and determined that habitat overlap with female caribou was slightly higher for coyote than for bear, while both predators had more similar habitat use (Figure 2). Risk for calves from coyotes mirrored variation in seasonal changes in habitat overlap, but had less association with co-occurrence. In contrast, yearly changes in habitat overlap during the calving season for black bears had little association with either co-occurrence patterns or overall risk for caribou neonates (Figure 2). These differences in space use overlap between two predators and a shared prey species speak to a high level of variability in the spatial interactions of generalist predators and their prey.

Predator hunting behaviour is a crucial element of the predator-prey game, shaping not only the behavioural response of the prey and the magnitude of non-consumptive effects, but also potentially having broader repercussions at the ecosystem level (Schmitz 2008). We found that population habitat overlap between coyotes and adult female caribou decreased as calves became less vulnerable to coyote predation (Figure 2), indicating that coyote space-use more closely matched caribou space-use when calves were susceptible to coyote predation. The overall lower level of population habitat overlap observed between bears and caribou (Figure 2) 
was probably also influenced by hunting behaviour. Our results also showed that the habitat overlap between bears and coyotes was greater than the habitat overlap between caribou and either predator, but that the similarity between predators was at its lowest during the period of greatest neonate vulnerability (Figure 2). These results indicate that bears, coyotes, and caribou are likely using more similar space-use strategies later in the season, perhaps providing a partial explanation for why risk for caribou neonates remains high for a longer period since coyotes colonized Newfoundland (Bastille-Rousseau et al. 2015).

Many populations of predators can be considered as groups of specialized individuals (Bolnick et al. 2003; Woo et al. 2008). In our study, both predator species displayed high intraspecific variation in individual habitat overlap with caribou; numerous individuals displayed little to no overlap, whereas some displayed strong overlap in habitat use. Although a high degree of similarity in habitat overlap between a predator and caribou may not be a formal indication of specialization, individuals with higher habitat overlap are more likely to prey on caribou (Basille et al. 2012). The minor influence of individual characteristics on habitat overlap (Figure S1, Supplementary material) and the low level of individual overlap are consistent with the notion that caribou are not primary prey for most individuals of either of these carnivores.

Predators exist along a continuum regarding specialization toward resources (Bolnick et al. 2003). At one extreme, specialists focus on primary prey exclusively, switching to alternate prey only during periods of low primary prey density (Fryxell and Lundberg 1994). Such preyswitching behaviour is well captured by current functional response models and, therefore, the integration of specialist predators in prey population dynamics is more straightforward (Vucetich et al. 2002). At the other extreme, generalist predators may specialize on a given prey 
type only in restricted space and/or time, but nevertheless orient their foraging behaviour toward a diversity of resources (Smout et al. 2010). This flexibility in searching behaviour increases the opportunity for opportunistic predation, resulting in the consumption of prey that is unintentionally encountered (Schmidt et al. 2001; Schmidt 2004). Even if ungulate neonates are an extremely profitable resource for these predators (Rode and Robbins 2000; Turner et al. 2011), the small overlap of both predators with caribou indicates that this particular prey type is unlikely to serve as primary prey. Indeed, movement patterns of bears and coyotes are likely influenced by the availability of other resources during the caribou calving season, including vegetation and potentially moose neonates. It is therefore unclear whether these predators are actively searching for neonates or are simply incidentally encountering them. Further examination of resource selection and functional response of coyotes and black bears towards calves is needed to clarify the role of caribou and moose in their diet and whether apparent competition is at play between the two ungulates (Holt and Lawton 1994).

Predation risk can be separated into two sub-components: the probability of encounter $(\alpha)$ and the probability of death following an encounter (Lima and Dill 1990; Hebblewhite et al. 2005). Space-use patterns of predator and prey comprise the main elements of the encounter component (Hebblewhite et al. 2005). For a neonate calf, vulnerability is highly influenced by age (Gustine et al. 2006). To some extent, we found that habitat use matched the encounter index for coyotes, but we found little correspondence between these indices for bears. Moreover, for coyotes, the overall patterns of overlap and encounter followed the change in risk (Figure 2). This may indicate that predation risk from coyotes was shaped by both the encounter probability and the change in neonate vulnerability. Results from bear were 
markedly different; overlap and encounter did not correspond with variation in risk (Figure 2), other than an extremely high encounter rate following neonate's birth. This indicates that risk from bear was almost uniquely driven by vulnerability of neonate caribou during the critical post-partum period, and that the habitat use of bears throughout the year had little influence on overall risk thereafter. This is corroborated by numerous studies showing a short period of vulnerability to bear predation for ungulate neonates (review by Zager and Beecham 2006). Nevertheless, it is interesting that these two different strategies resulted in similar levels of cause-specific predation rates (Lewis and Mahoney 2014).

Newfoundland caribou have been in a state of protracted decline since the mid-1990s following a numerical increase initiated in the 1970s (Bastille-Rousseau et al. 2013). Just prior to this decline, coyotes colonized the island and became widespread by the late 1990s. Factors ultimately driving the caribou population decline were related to the high population size and a decrease in summer foraging and harsher winter conditions (Bastille-Rousseau et al. 2013), but proximately, this decline is the outcome of a drastic reduction in neonate survival (Lewis and Mahoney 2014). It is commonly accepted that generalist predators can stabilize prey populations when mortality is density-dependent (Fryxell and Lundberg 1994), but local extinction may result when predators expand their diet rather than switch to alternate prey (Holt and Lawton 1994). Mortalities do not appear to be density-dependent for adult female Newfoundland caribou following the caribou population decline but caribou are one of many food items consumed by bears and coyotes (C. Zieminski unpublished data; Bridger 2005). This suggests that per-capita predation of caribou is unlikely to decrease even if the population continues to decline. As our analysis was limited to a period when caribou populations were at 
their lowest density in the last 3 decades, it is uncertain whether predators may alter their behaviour by increasing the predation rate on caribou following a positive change in abundance. This would represent a double-edged sword for Newfoundland caribou, as densityindependent predation may threaten current caribou persistence whereas density-dependent predation may limit future population increase.

A great deal of literature on predator-prey interactions has focused on systems involving specialist predators. Detailed spatial models of the behavioural games for both species, or formulations of several types of functional responses, greatly improved the study of predatorprey interactions (Vucetich et al. 2002; Hebblewhite et al. 2005). However, the behavioural strategies of generalist consumers are not easily captured by these theoretical models. Our work illustrates how risk for a specific prey species is affected by generalist predators that display different strategies regarding patterns in habitat overlap and co-occurrence. Moreover, we demonstrated that these strategies may be highly variable between species, but nevertheless have a similar impact on prey population dynamics. As top predators decline worldwide (Johnson et al. 2007; Heithaus et al. 2008), it is likely that the predation impact on prey communities will be increasingly driven by highly opportunistic and generalist predators with an increased ability to respond dynamically to human development and landscape alteration (Prugh et al. 2009). It is therefore crucial that we develop a robust theoretical foundation for predator-prey interactions involving generalist predators to better predict future influences on ecosystem function. 


\section{Acknowledgements}

This work was supported by the Institute for Biodiversity, Ecosystem Science \& Sustainability; the Sustainable Development \& Strategic Science Division of the Newfoundland \& Labrador Department of Environment \& Conservation; the Safari Club International Foundation; and by a scholarship from the Natural Sciences and Engineering Research Council of Canada to GBR. This project was a component of the Newfoundland \& Labrador Caribou Strategy 2008-2013. We thank Keith P. Lewis for comments on an earlier version of this manuscript. We thank the Newfoundland \& Labrador Department of Environment \& Conservation for providing these long-term data as well as the many government personnel involved in the animal captures and monitoring over the last 4 decades. 


\section{References}

Basille, M., Fortin, D., Dussault, C., Ouellet, J.-P., and Courtois, R. 2012. Ecologically based definition of seasons clarifies predator-prey interactions. Ecography, 36(2): 220-229. Blackwell Publishing Ltd. doi: 10.1111/j.1600-0587.2011.07367.x.

Bastille-Rousseau, G., Fortin, D., Dussault, C., Courtois, R., and Ouellet, J.-P.P. 2011. Foraging strategies by omnivores: Are black bears actively searching for ungulate neonates or are they simply opportunistic predators? Ecography, 34(4): 588-596. doi: 10.1111/j.16000587.2010.06517.x.

Bastille-Rousseau, G., Schaefer, J.A., Lewis, K.P., Mumma, M., Ellington, E.H., Rayl, N.D., Mahoney, S.P., Pouliot, D., and Murray, D.L. 2015. Phase-dependent climate-predator interactions explain three decades of variation in neonatal caribou survival. J. Anim. Ecol. doi: $10.1111 / 1365-2656.12466$.

Bastille-Rousseau, G., Schaefer, J.A., Mahoney, S.P., and Murray, D.L. 2013. Population decline in semi-migratory caribou (Rangifer tarandus): intrinsic or extrinsic drivers? Can. J. Zool. 91(11): 820-828. doi: doi:10.1139/cjz-2013-0154.

Bolnick, D.I., Svanbäck, R., Fordyce, J. a, Yang, L.H., Davis, J.M., Hulsey, C.D., and Forister, M.L. 2003. The ecology of individuals: incidence and implications of individual specialization. Am. Nat. 161(1): 1-28. doi: 10.1086/343878.

Bridger, K.E. 2005. A comparative study of the dietary habits and helminth fauna of Canada lynx (Lynx canadensis), Red fox (Vulpes vulpes), and Eastern coyote (Canis latrans) on insular Newfoundland. M.Sc thesis. Department of Biology. Memorial University of Newfoundland. St. John's, NL.

Brown, J. 1999. Vigilance, patch use and habitat selection: foraging under predation risk. Evol. Ecol. Res. 1(1999): 49-71.

Brown, J.S., Laundré, J.W., and Gurung, M. 1999. The ecology of fear: optimal foraging, game theory, and trophic interactions. J. Mammal. 80(2): 385-399.

Chamaillé-Jammes, S., Malcuit, H., Le Saout, S., and Martin, J.-L. 2014. Innate threat-sensitive foraging: black-tailed deer remain more fearful of wolf than of the less dangerous black bear even after 100 years of wolf absence. Oecologia, 174(4): 1151-8. doi: 10.1007/s00442013-2843-0.

Chesson, P., and Kuang, J.J. 2008. The interaction between predation and competition. Nature, 456(7219): 235-8. doi: 10.1038/nature07248.

Environment Canada. 2013. National Climate Data and Information Archive. Available from http://climate.weatheroffice.gc.ca/Welcome_e.html. [November 2013]. 
Festa-Bianchet, M., Coulson, T., Gaillard, J.M., Hogg, J.T., and Pelletier, F. 2006. Stochastic predation events and population persistence in bighorn sheep. Proc. R. Soc. Lond. B Biol. Sci. 273(1593): 1537-1543. doi: 10.1098/rspb.2006.3467.

Fryxell, J.M., and Lundberg, P. 1994. Diet choice and predator-prey dynamics. Evol. Ecol. 8(4): 407-421. doi: 10.1007/BF01238191.

Getz, W.M. 2011. Biomass transformation webs provide a unified approach to consumerresource modelling. Ecol. Lett. 14(2): 113-124. doi: 10.1111/j.1461-0248.2010.01566.x.

Griffin, K.A., Hebblewhite, M., Robinson, H.S., Zager, P., Barber-Meyer, S.M., Christianson, D., Creel, S., Harris, N.C., Hurley, M.A., Jackson, D.H., Johnson, B.K., Myers, W.L., Raithel, J.D., Schlegel, M., Smith, B.L., White, C., and White, P.J. 2011. Neonatal mortality of elk driven by climate, predator phenology and predator community composition. J. Anim. Ecol. 80(6): 1246-1257. doi: 10.1111/j.1365-2656.2011.01856.x.

Gustine, D.D., Parker, K.K.L., Lay, R.R.J., Gillingham, M.P., and Heard, D.C. 2006. Calf survival of woodland caribou in a multi-predator ecosystem. Wildl. Monogr. 165(1): 1-32.

Hebblewhite, M., Merrill, E.H., and McDonald, T.L. 2005. Spatial decomposition of predation risk using resource selection functions: An example in a wolf-elk predator-prey system. Oikos, 111(1): 101-111.

Heithaus, M.R., Frid, A., Wirsing, A.J., and Worm, B. 2008. Predicting ecological consequences of marine top predator declines. Trends Ecol. Evol. 23(4): 202-210. doi: 10.1016/j.tree.2008.01.003.

Holt, R.D., and Lawton, J.H. 1994. The ecological consequences of shared natural enemies. Annu. Rev. Ecol. Syst. 25: 495-520.

Johnson, C.N., Isaac, J.L., and Fisher, D.O. 2007. Rarity of a top predator triggers continentwide collapse of mammal prey: dingoes and marsupials in Australia. Proc. R. Soc. Lond. B Biol. Sci. 274(1608): 341-6. doi: 10.1098/rspb.2006.3711.

Latombe, G., Fortin, D., and Parrott, L. 2013. Spatio-temporal dynamics in the response of woodland caribou and moose to the passage of grey wolf. J. Anim. Ecol. 83(1): 185-198. doi: 10.1111/1365-2656.12108.

Laundré, J.W., Hernandez, L., and Altendorf, K.B. 2001. Wolves, elk, and bison: reestablishing the" landscape of fear" in Yellowstone National Park, USA. Can. J. Zool. 79(8): 14011409.

Lewis, K.P., and Mahoney, S.P. 2014. Caribou survival, fate, and cause of mortality in Newfoundland: a summary and analysis of the patterns and causes of caribou survival and mortality in Newfoundland during a period of rapid population decline (2003-2012). 
Technical Bulletin No. 009. Sustainable Development and Strategic Science, Department of Environment and Conservation, Government of Newfoundland and Labrador, St. John's, Canada.

Lima, S.L., and Dill, L.M. 1990. Behavioral decisions made under the risk of predation - A review and prospectus. Can. J. Zool. 68(4): 619-640.

Mitchell, W.A., and Lima, S.L. 2002. Predator-prey shell games: Large-scale movement and its implications for decision-making by prey. Oikos, 99(2): 249-259.

Muhly, T.B., Alexander, M., Boyce, M.S., Creasey, R., Hebblewhite, M., Paton, D., Pitt, J.A., and Musiani, M. 2010. Differential risk effects of wolves on wild versus domestic prey have consequences for conservation. Oikos, 119(8): 1243-1254. doi: 10.1111/j.16000706.2009.18350.x.

Preisser, E.L., Orrock, J.L., and Schmitz, O.J. 2007. Predator hunting mode and habitat domain alter nonconsumptive effects in predator-prey interactions. Ecology, 88(11): 2744-2751.

Prugh, L.R., Stoner, C.J., Epps, C.W., Bean, W.T., Ripple, W.J., Laliberte, A.S., and Brashares, J.S. 2009. The Rise of the Mesopredator. Bioscience 59(9): 779-791. doi: 10.1525/bio.2009.59.9.9.

Rode, K.D., and Robbins, C.T. 2000. Why bears consume mixed diets during fruit abundance. Can. J. Zool. 78(9): 1640-1645.

Roff, D. 1996. The evolution of threshold traits in animals. Q. Rev. Biol. 71(1): 3-35.

Schmidt, K.A. 2004. Incidental predation, enemy-free space and the coexistence of incidental prey. Oikos, 106(2): 335-343.

Schmidt, K.A., Goheen, J.R., and Naumann, R. 2001. Incidental nest predation in songbirds: behavioral indicators detect ecological scales and processes. Ecology, 82(10): 2937-2947.

Schmitz, O.J. 2005. Behavior of predators and prey and links with population-level processes. In Ecology of predator-prey interactions. Edited by P. Barbosa and I. Castellanos. Oxford University Press, New York, New York, USA.

Schmitz, O.J. 2008. Effects of predator hunting mode on grassland ecosystem function. Science, (80-. ). 319(5865): 952-954. doi: 10.1126/science.1152355.

Sih, A. 1984. The behavioral response race between predator and prey. Am. Nat. 123(1): 143150.

Sikes, R.S., and Gannon, W.L. 2011. Guidelines of the American Society of Mammalogists for the use of wild mammals in research. J. Mammal. 92(1): 235-253.

Smout, S., Asseburg, C., Matthiopoulos, J., Fernández, C., Redpath, S., Thirgood, S., and 
Harwood, J. 2010. The functional response of a generalist predator. PLoS One, 5(5): e10761. doi: 10.1371/journal.pone.0010761.

Stephens, D.W., and Krebs, J.R. 1986. Foraging theory. Princeton University Press, Princeton, New Jersey.

Turner, M.M., Rockhill, A.P., DePerno, C.S., Jenks, J. a., Klaver, R.W., Jarding, A.R., Grovenburg, T.W., and Pollock, K.H. 2011. Evaluating the effect of predators on whitetailed deer: Movement and diet of coyotes. J. Wildl. Manage. 75(4): 905-912. doi: 10.1002/jwmg.109.

Vucetich, J., Peterson, R., and Schaefer, C. 2002. The effect of prey and predator densities on wolf predation. Ecology, 83(11): 3003-3013.

Weir, J.N., Morrison, S.F., Luther, J.G., and Mahoney, S.P. 2014. Caribou data synthesis Progress Report \#2. Status of the Newfoundland population of woodland caribou. Technical Bulletin No. 008. Sustainable Development and Strategic Science, Department of Environment and Conservation, Government of Newfoundland and Labrador, St. John's, Canada.

Whittington, J., Hebblewhite, M., DeCesare, N.J., Neufeld, L., Bradley, M., Wilmshurst, J., and Musiani, M. 2011. Caribou encounters with wolves increase near roads and trails: A timeto-event approach. J. Appl. Ecol. 48: 1535-1542. doi: 10.1111/j.1365-2664.2011.02043.x.

Woo, K.J., Elliott, K.H., Davidson, M., Gaston, A.J., and Davoren, G.K. 2008. Individual specialization in diet by a generalist marine predator reflects specialization in foraging behaviour. J. Anim. Ecol. 77(6): 1082-1091. doi: 10.1111/j.1365-2656.2008.01429.x.

Yan, M., and Ye, K. 2007. Determining the number of clusters using the weighted gap statistic. Biometric,s 63(4): 1031-1037. doi: 10.1111/j.1541-0420.2007.00784.x.

Zager, P., and Beecham, J. 2006. The role of American black bears and brown bears as predators on ungulates in North America. Ursus, 17(2): 95-108. 


\section{Figures}

Figure legends.

Figure 1. Graphical representation of the biological seasons for caribou (Rangifer tarandus L. 1758), black bear (Ursus americanus Pallas, 1780) and coyote (Canis latrans Say, 1823) on insular Newfoundland. Shading indicates months.

Figure 2. Temporal changes in habitat overlap (top-panels) and in the index of population level habitat overlap, encounter rate, and hazard risk (middle panels) of caribou (Rangifer tarandus L. 1758) and their two main predators, with temporal changes in habitat overlap between bears (Ursus americanus Pallas, 1780) and coyotes (Canis latrans Say, 1823) (bottom panel). For habitat overlap, population-level overlap (solid line) and average individual-level (dashed line) habitat overlap were based on habitat use; grey areas represent $90 \%$ quantiles of individual overlap in the top-panels. Note that the x-axis starts in June for the middle-panels and is truncated at the denning period for bears. 
Figure 1.

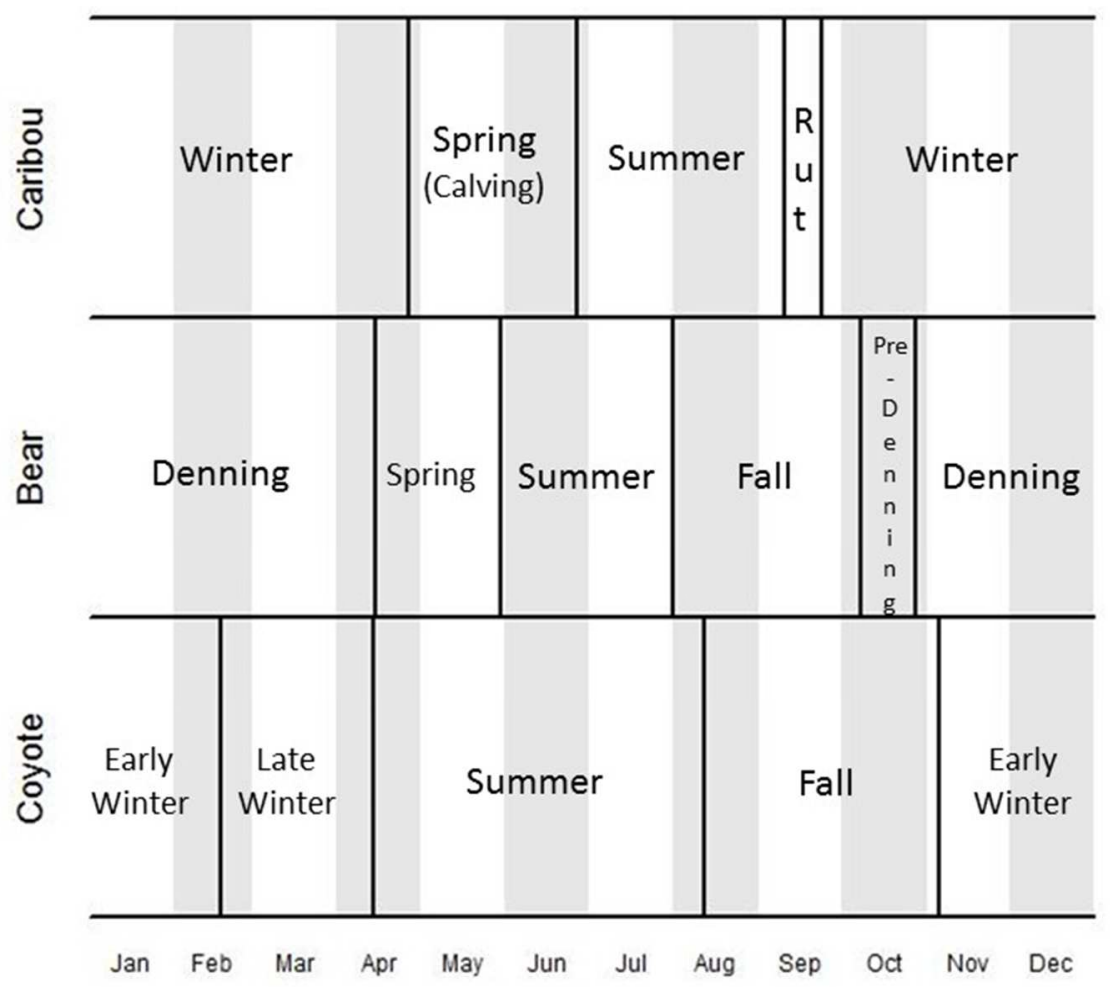


Figure 2.
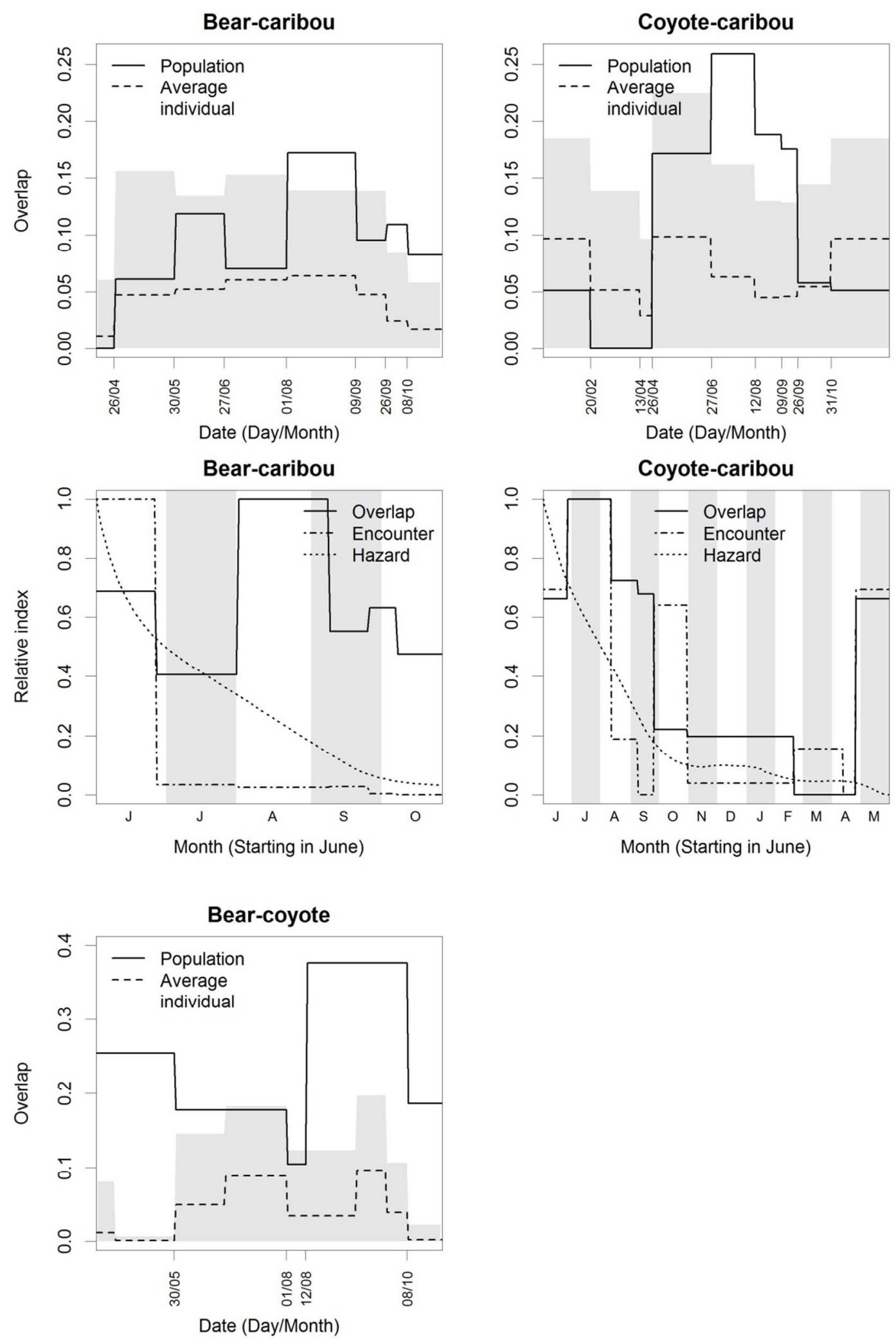
4 Table S1. Linear models between predator individual resource overlap with caribou (Rangifer tarandus L. 1758) and predator

5 characteristics for 55 black bears (Ursus americanus Pallas, 1780) and 61 coyotes (Canis latrans Say, 1823), Newfoundland, 2006-

6 2013. Parameters estimates with standard errors and model $R_{2}$ are presented for models run on each predators-caribou seasons.

7 Differences detected at $p=0.05$ are in bold.

\begin{tabular}{|c|c|c|c|c|c|c|c|c|}
\hline ear & & & & & & & & \\
\hline & $15 / 04-26 / 04$ & $27 / 04-30 / 05$ & $31 / 05-27 / 06$ & $28 / 06-01 / 08$ & $02 / 08-09 / 09$ & $10 / 09-24 / 09$ & $26 / 09-08 / 10$ & $09 / 10-28 / 10$ \\
\hline Intercept & $0.006(0.004)$ & $0.034(0.01)$ & $0.049(0.011)$ & $0.062(0.013)$ & $0.071(0.011)$ & $0.031(0.011)$ & $0.025(0.008)$ & $0.019(0.004)$ \\
\hline Adult & $0.000(0.005)$ & $0.010(0.013)$ & $-0.005(0.014)$ & $-0.014(0.016)$ & $-0.012(0.014)$ & $0.011(0.013)$ & $-0.001(0.009)$ & $-0.006(0.005)$ \\
\hline Male & $0.002(0.005)$ & $0.009(0.013)$ & $0.008(0.015)$ & $0.009(0.017)$ & $0.002(0.014)$ & $0.030(0.014)$ & $0.000(0.010)$ & $-0.004(0.006)$ \\
\hline Adult:Male & $0.004(0.006)$ & $-0.007(0.016)$ & $0.002(0.018)$ & $0.001(0.021)$ & $-0.003(0.017)$ & $-0.023(0.017)$ & $0.003(0.012)$ & $0.011(0.007)$ \\
\hline R2 & 0.065 & 0.019 & 0.029 & 0.049 & 0.053 & 0.098 & 0.004 & 0.078 \\
\hline
\end{tabular}

\begin{tabular}{|c|c|c|c|c|c|c|c|c|}
\hline & $21 / 02-13 / 04$ & $14 / 04-26 / 04$ & $27 / 04-27 / 06$ & $28 / 06-12 / 08$ & $13 / 08-09 / 09$ & $10 / 09-26 / 09$ & $27 / 09-31 / 10$ & $01 / 11-20 / 02$ \\
\hline Intercept & $0.037(0.026)$ & $0.099(0.020)$ & $0.043(0.018)$ & $0.16(0.035)$ & $0.101(0.027)$ & $0.035(0.021)$ & $0.02(0.023)$ & $0.025(0.021)$ \\
\hline Adult & $0.046(0.027)$ & $-0.05(0.021)$ & $-0.001(0.019)$ & $-0.046(0.037)$ & $-0.045(0.029)$ & $0.013(0.022)$ & $0.015(0.024)$ & $0.046(0.023)$ \\
\hline Male & $0.043(0.029)$ & $-0.052(0.022)$ & $-0.016(0.02)$ & $-0.079(0.039)$ & $-0.048(0.031)$ & $0.006(0.023)$ & $0.016(0.026)$ & $0.015(0.024)$ \\
\hline Resident & $0.007(0.016)$ & $-0.01(0.012)$ & $-0.006(0.011)$ & $-0.015(0.021)$ & $0.008(0.017)$ & $0.001(0.013)$ & $0.026(0.014)$ & $0.01(0.013)$ \\
\hline Adult:Male & $-0.026(0.033)$ & $0.056(0.026)$ & $0.005(0.023)$ & $0.073(0.045)$ & $0.046(0.035)$ & $-0.014(0.027)$ & $-0.013(0.03)$ & $-0.031(0.028)$ \\
\hline $\mathrm{R} 2$ & 0.121 & 0.13 & 0.028 & 0.086 & 0.087 & 0.01 & 0.076 & 0.124 \\
\hline
\end{tabular}



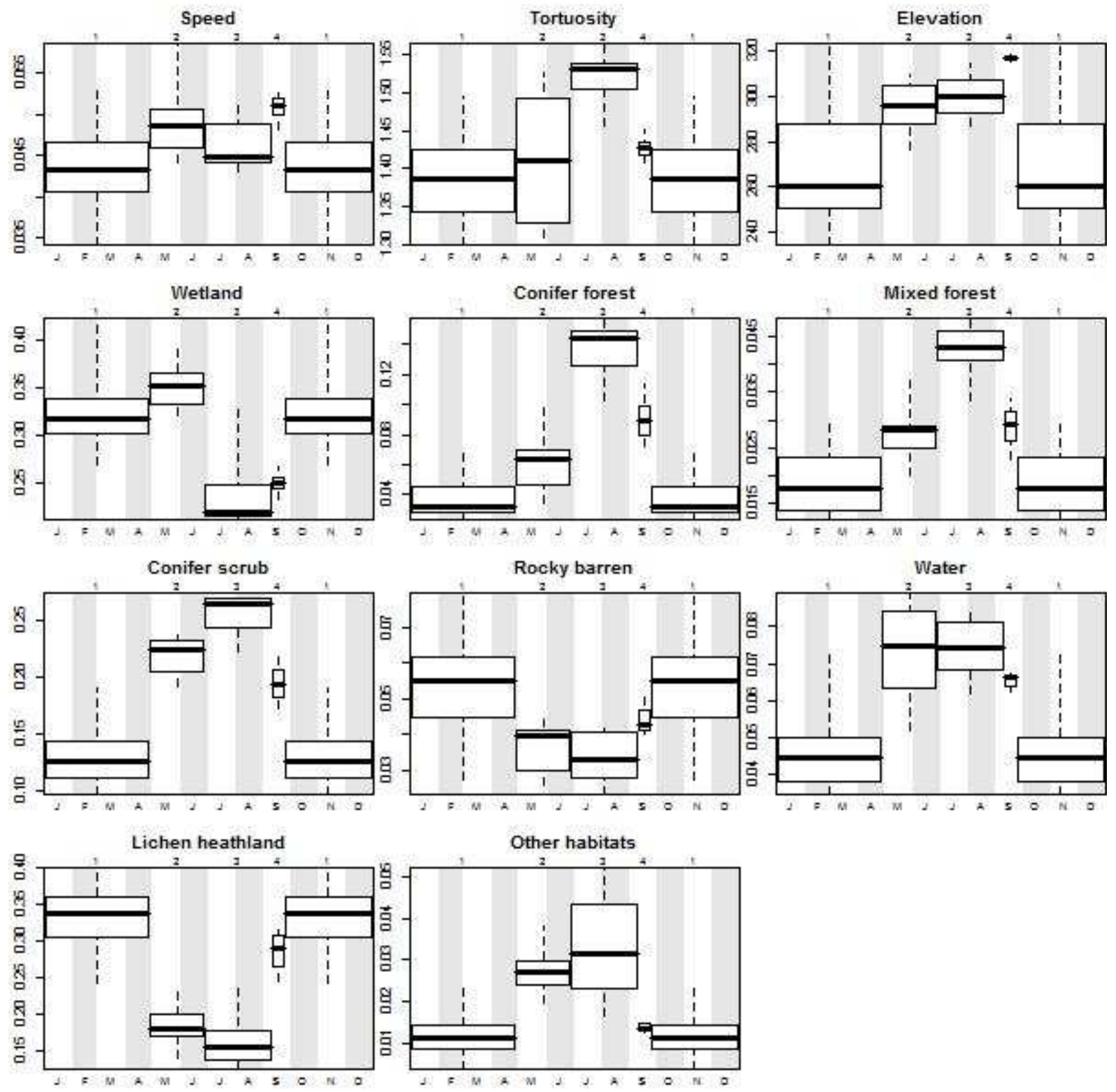

Figure S1. K-means associated with the multi-layer approach delineated 4 seasons during the year for 146 caribou (Rangifer tarandus L. 1758) in Newfoundland, 20062013. Variation in movement parameters and resource use variables can be seen throughout the year. Note that the winter season overlaps the end and the beginning of the year. 

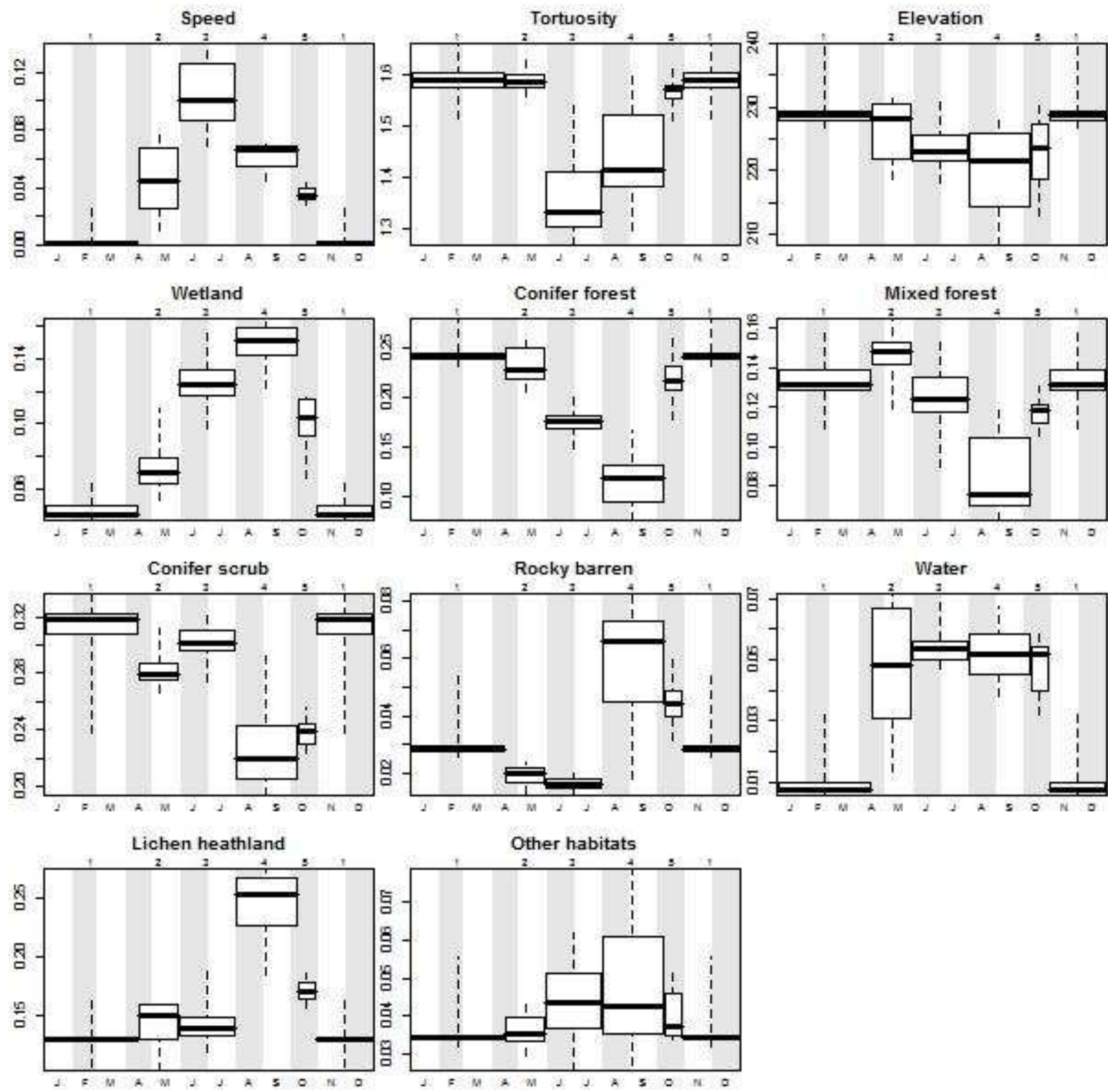

Figure S2. K-means associated with the multi-layer approach delineated 5 seasons during the year for 55 bears (Ursus americanus Pallas, 1780) in Newfoundland, 20062013. Variation in movement parameters and resource use variables can be seen throughout the year. Note that the denning season overlaps the end and the beginning of the year. 

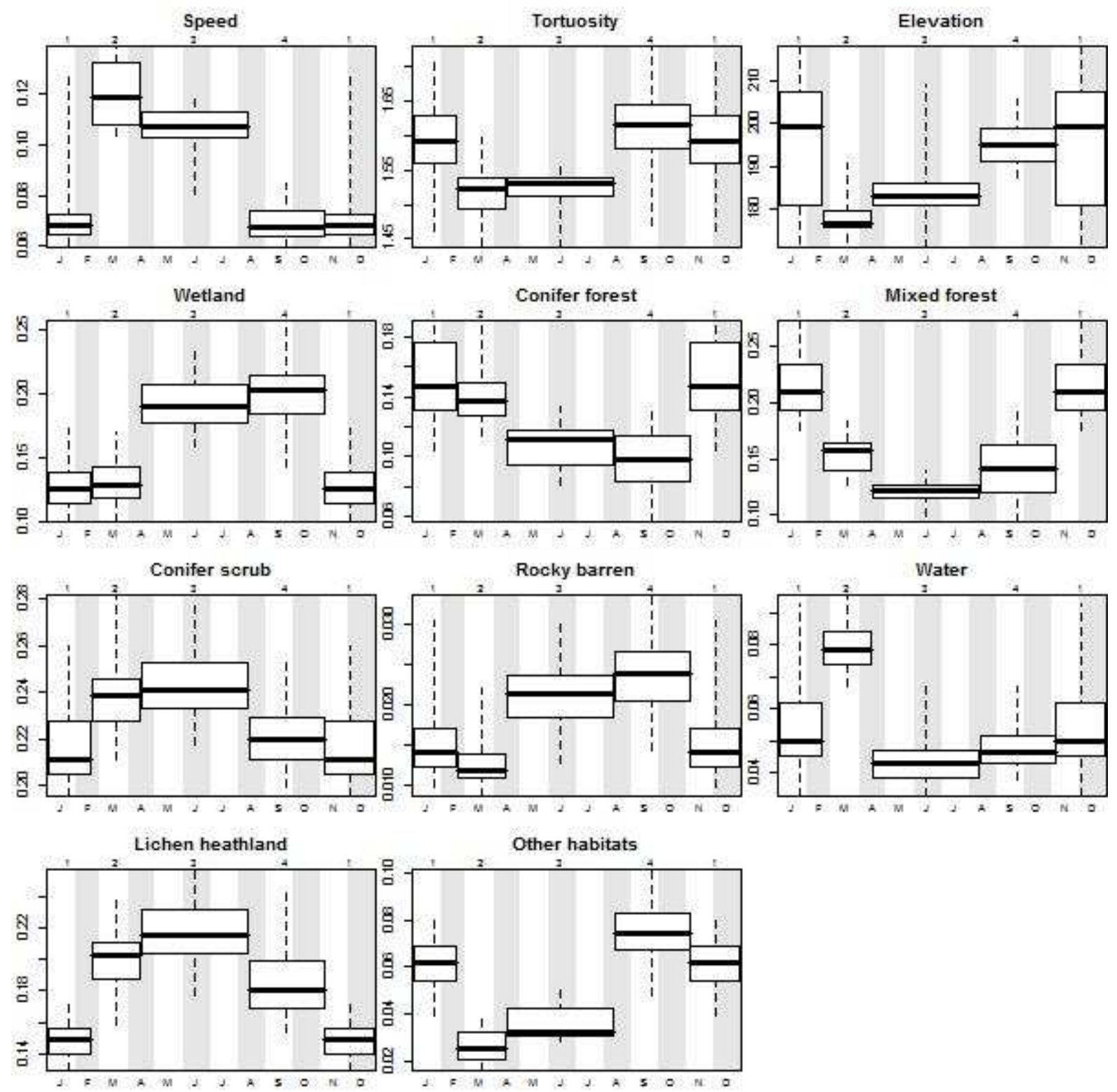

Figure S3. K-means associated with the multi-layer approach delineated 4 seasons during the year for 61 coyotes (Canis latrans Say, 1823) in Newfoundland, 2006-2013. Variation in movement parameters and resource use variables can be seen throughout the year. Note that the winter season overlaps the end and the beginning of the year. 